\title{
Relapses of sarcoidosis: what are they and can we predict who will get them?
}

\author{
Robert P. Baughman ${ }^{1}$ and Marc A. Judson² \\ Affiliations: 'Internal Medicine, University of Cincinnati Medical Center, Cincinnati, $\mathrm{OH}$, and ${ }^{2}$ Pulmonary and \\ Critical Care Medicine, Medical Center of Albany, Albany, NY, USA.
}

Correspondence: R.P. Baughman, Internal Medicine, University of Cincinnati Medical Center, 1001 Holmes Eden Ave, Cincinnati 45267, OH, USA. E-mail: baughmrpducmail.uc.edu

$\boldsymbol{0}$ @ERSpublications

Can one predict who will relapse from sarcoidosis? http://ow.ly/qYAP2

Granulomatous inflammation in the lung may occur from a variety of causes. Many of these are the result of specific antigens that reach the lung and induce a granulomatous response. A prototype of this schema is pulmonary tuberculosis where the organism serves as the inciting antigen. Treatment of tuberculosis is aimed at killing and clearing the organism. It would be foolhardy and potentially lethal to solely treat the granulomatous inflammation of tuberculosis with immunosuppressive anti-granulomatous medications.

Sarcoidosis is, obviously, very different. The cause of sarcoidosis is unknown and treatment directed against the granulomatous inflammation is effective [1]. When anti-sarcoidosis medications are withdrawn, relapse is very common. Reported relapse rates of sarcoidosis range from $13 \%$ to $75 \%$ depending on the population studied [2-5]. These relapses typically occur 1 month to 1 year after therapy is tapered or discontinued $[4,5]$.

In most studies, the definition of relapse has been vague. In some cases, recurrence of the disease may be considered an acute exacerbation of the sarcoidosis [6]. In other situations, the disease may have never really been under control, but simply the manifestation became more apparent as anti-inflammatory drugs were withdrawn. In addition, progression of sarcoidosis is not well defined. We propose a series of criteria to define progression of the disease (table 1). These include a significant need to increase systemic antiinflammatory medications, for example increasing the dose of glucocorticoids or the addition of other agents such as infliximab. This would not include the addition of a new agent simply for steroid sparing. In sarcoidosis patients with disease for the past 5 years, about $10 \%$ will have had an increase in their antiinflammatory medicines in the previous year [7]. A worsening of chest imaging has been seen in many, but not all, patients with clinical worsening. A worsening of imaging correlated with worsening pulmonary function [8-10]. A clinically significant change in pulmonary function has been reported with several treatments for worsening sarcoidosis [11]. Changes in forced vital capacity and diffusing capacity of the lung for carbon monoxide are associated with increased mortality in idiopathic pulmonary fibrosis [12]. A major predictor of need for chronic therapy has been dyspnoea [13]. We feel that the presence of one or more of these features would be considered progression of the disease.

Interestingly, one of the risk factors associated with a high rate of sarcoidosis relapse is the previous use of corticosteroids $[4,14]$. In addition, a risk factor for continued use of corticosteroid therapy 2 years after the diagnosis of sarcoidosis is use of corticosteroids at the initial visit [13]. Recent genetic studies have indicated that the presence of certain human leukocyte antigens or other factors is associated with a high rate of spontaneous resolution [15] or chronic disease [16-18].

The data above suggest that these exacerbations of sarcoidosis may possibly not truly be relapses, but rather situations where the disease never really "left" and the granulomatous response to whatever causes sarcoidosis was only temporarily compromised while immunosuppressive therapy was being used. Since we

Received: Aug 092013 | Accepted after revision: Nov 052013

Conflict of interest: Disclosures can be found alongside the online version of this article at www.erj.ersjournals.com

Copyright (CERS 2014 


\section{TABLE 1 Definition of progression of sarcoidosis}

Significant increase in systemic medication

Worsening of chest imaging

Worsening of pulmonary function status

Worsening of dyspnoea

do not know if sarcoidosis is caused by antigens, much less any specific ones, it is not presently possible to determine when the "cause" of sarcoidosis has been cleared and the disease is truly in remission. Unfortunately, all of our previously available markers for active granulomatous inflammation in sarcoidosis, including serum angiotensin-converting enzyme [19], gallium-67 scan results [20] and bronchoalveolar lavage analysis [21], are often suppressed on effective therapy and are not predictive of relapse. In particular gallium-67 uptake is rapidly suppressed by glucocorticoids independent of the effect of glucocorticoids on the sarcoidosis itself [20].

Infliximab has proved an effective form of therapy for refractory pulmonary and extrapulmonary disease [22-24]. However, infliximab treatment often has to be stopped due to allergic reactions, infections or cost issues $[25,26]$. Sarcoidosis patients treated with infliximab appear to have a very high likelihood of relapse of their disease when the drug is discontinued $[27,28]$. In one study in which the drug was withdrawn after 1 year or less, $90 \%$ of patients had recurrence of their symptomatic disease [28]. This high rate of relapse is similar to what has been recorded in rheumatoid arthritis patients [29].

It is against this backdrop that VORSELAARs et al. [30] report their retrospective analysis concerning the outcome of 47 sarcoidosis patients who discontinued infliximab therapy. The study proposed to stop the drug after 6 months in all patients. $62 \%$ of patients experienced a relapse of disease after drug withdrawal. With this large and well-defined population, the authors were able to examine several potential markers for predicting relapse. The soluble interleukin (IL)-2 receptor and ${ }^{18} \mathrm{~F}$-fluorodeoxyglucose (FDG) positron emission tomography (PET) scan at the end of infliximab treatment were independent predictors of relapse.

The soluble IL-2 receptor reflects the activation of CD4 T-lymphocytes and others have reported it as a marker of disease activity [31,32]. In comparison to other serum markers, it appears to be as predictive of disease activity $[33,34]$. It has also been found to be complimentary to FDG PET scanning by other authors [35]. However, the marker has some variability and is not specific for lung disease [33].

The FDG PET scan has the advantage of detecting organ specific inflammation [36]. Previous reports have indicated that presence of parenchymal lung activity is associated with clinical deterioration over the next 6 months $[37,38]$. Unlike the gallium scan, which is suppressed by glucocorticoids, FDG PET scans can remain markedly positive in sarcoidosis patients who are failing treatment [39]. Thus, FDG PET appears useful in assessing the response to treatment in refractory sarcoidosis.

The study by VORSELAARS et al. [30] demonstrates the utility of soluble IL-2 receptor and FDG PET scanning in managing sarcoidosis patients. Further studies will be needed to confirm this observation, but these findings may have major clinical and financial impact. While the FDG PET scan is an expensive test, the judicious use of FDG PET may allow the clinician to discontinue an even more expensive, as well as potentially more dangerous, treatment regimen. Furthermore, persistence of soluble IL-2 receptor elevation and positive FDG PET scan findings support the notion that many sarcoidosis relapses actually represent chronic disease that was suppressed by immunosuppression and remission was really never achieved.

\section{References}

1 Cottin V, Müller-Quernheim J. Sarcoidosis from bench to bedside: a state-of-the-art series for the clinician. Eur Respir J 2012; 40: 14-16.

2 Johns CJ, Michele TM. The clinical management of sarcoidosis. A 50-year experience at the Johns Hopkins hospital. Medicine (Baltimore) 1999; 78: 65-111.

3 Hunninghake GW, Gilbert S, Pueringer R, et al. Outcome of the treatment for sarcoidosis. Am J Respir Crit Care Med 1994; 149: 893-898.

4 Gottlieb JE, Israel HL, Steiner RM, et al. Outcome in sarcoidosis. The relationship of relapse to corticosteroid therapy. Chest 1997; 111: 623-631.

5 Rizzato G, Montemurro L, Colombo P. The late follow-up of chronic sarcoid patients previously treated with corticosteroids. Sarcoidosis Vasc Diffuse Lung Dis 1998; 15: 52-58.

Panselinas E, Judson MA. Acute pulmonary exacerbations of sarcoidosis. Chest 2012; 142: 827-836.

Baughman RP, Nagai S, Balter M, et al. Defining the clinical outcome status (COS) in sarcoidosis: results of WASOG Task Force. Sarcoidosis Vasc Diffuse Lung Dis 2011; 28: 56-64.

8 McKinzie BP, Bullington WM, Mazur JE, et al. Efficacy of short-course, low-dose corticosteroid therapy for acute pulmonary sarcoidosis exacerbations. Am J Med Sci 2010; 339: 1-4. 
9 Zappala CJ, Desai SR, Copley SJ, et al. Optimal scoring of serial change on chest radiography in sarcoidosis. Sarcoidosis Vasc Diffuse Lung Dis 2011; 28: 130-138.

10 Nunes H, Uzunhan Y, Gille T, et al. Imaging of sarcoidosis of the airways and lung parenchyma and correlation with lung function. Eur Respir J 2012; 40: 750-765.

11 Baughman RP, Nunes H, Sweiss NJ, et al. Established and experimental medical therapy of pulmonary sarcoidosis. Eur Respir J 2013; 41: 1424-1438.

12 Zappala CJ, Latsi PI, Nicholson AG, et al. Marginal decline in forced vital capacity is associated with a poor outcome in idiopathic pulmonary fibrosis. Eur Respir J 2010; 35: 830-836.

13 Baughman RP, Judson MA, Teirstein A, et al. Presenting characteristics as predictors of duration of treatment in sarcoidosis. QJM 2006; 99: 307-315.

14 Rodrigues SC, Rocha NA, Lima MS, et al. Factor analysis of sarcoidosis phenotypes at two referral centers in Brazil. Sarcoidosis Vasc Diffuse Lung Dis 2011; 28: 34-43.

15 Grunewald J, Eklund A. Löfgren's syndrome: human leukocyte antigen strongly influences the disease course. Am J Respir Crit Care Med 2009; 179: 307-312.

16 Veltkamp M, Van Moorsel CH, Rijkers GT, et al. Genetic variation in the Toll-like receptor gene cluster (TLR10TLR1-TLR6) influences disease course in sarcoidosis. Tissue Antigens 2012; 79: 25-32.

17 Spagnolo P, Grunewald J. Recent advances in the genetics of sarcoidosis. J Med Genet 2013; 50: 290-297.

18 Pabst S, Fränken T, Schönau J, et al. Transforming growth factor- $\beta$ gene polymorphisms in different phenotypes of sarcoidosis. Eur Respir J 2011; 38: 169-175.

19 Baughman RP, Ploysongsang Y, Roberts RD, et al. Effects of sarcoid and steroids on angiotensin-converting enzyme. Am Rev Respir Dis 1983; 128: 631-633.

20 Köhn H, Klech H, Mostbeck A, et al. 67Ga scanning for assessment of disease activity and therapy decisions in pulmonary sarcoidosis in comparison to chest radiography, serum ACE and blood T-lymphocytes. Eur J Nucl Med 1982; 7: 413-416.

21 Keir G, Wells AU. Assessing pulmonary disease and response to therapy: which test? Semin Respir Crit Care Med 2010; 31: 409-418.

22 Baughman RP, Drent M, Kavuru M, et al. Infliximab therapy in patients with chronic sarcoidosis and pulmonary involvement. Am J Respir Crit Care Med 2006; 174: 795-802.

23 Judson MA, Baughman RP, Costabel U, et al. Efficacy of infliximab in extrapulmonary sarcoidosis: results from a randomised trial. Eur Respir J 2008; 31: 1189-1196.

24 Stagaki E, Mountford WK, Lackland DT, et al. The treatment of lupus pernio: results of 116 treatment courses in 54 patients. Chest 2009; 135: 468-476.

25 Blum MA, Koo D, Doshi JA. Measurement and rates of persistence with and adherence to biologics for rheumatoid arthritis: a systematic review. Clin Ther 2011; 33: 901-913.

26 Markatseli TE, Alamanos Y, Saougou I, et al. Survival of TNF- $\alpha$ antagonists in rheumatoid arthritis: a long-term study. Clin Exp Rheumatol 2012; 30: 31-38.

27 Panselinas E, Rodgers JK, Judson MA. Clinical outcomes in sarcoidosis after cessation of infliximab treatment. Respirology 2009; 14: 522-528.

28 Baughman RP, Lower EE, Ingledue R, et al. Management of ocular sarcoidosis. Sarcoidosis Vasc Diffuse Lung Dis 2012; 29: 26-33.

29 van der Maas A, Kievit W, van den Bemt BJ, et al. Down-titration and discontinuation of infliximab in rheumatoid arthritis patients with stable low disease activity and stable treatment: an observational cohort study. Ann Rheum Dis 2012; 71: 1849-1854.

30 Vorselaars ADM, Verwoerd A, van Moorsel CHM, et al. Prediction of relapse after discontinuation of infliximab therapy in severe sarcoidosis. Eur Respir J 2014; 43: 602-609.

31 Rothkrantz-Kos S, Dieijen-Visser MP, Mulder PG, et al. Potential usefulness of inflammatory markers to monitor respiratory functional impairment in sarcoidosis. Clin Chem 2003; 49: 1510-1517.

32 Ziegenhagen MW, Benner UK, Zissel G, et al. Sarcoidosis: TNF- $\alpha$ release from alveolar macrophages and serum level of sIL-2R are prognostic markers. Am J Respir Crit Care Med 1997; 156: 1586-1592.

33 Bargagli E, Bianchi N, Margollicci M, et al. Chitotriosidase and soluble IL-2 receptor: comparison of two markers of sarcoidosis severity. Scand J Clin Lab Invest 2008; 68: 479-483.

34 Miyoshi S, Hamada H, Kadowaki T, et al. Comparative evaluation of serum markers in pulmonary sarcoidosis. Chest 2010; 137: 1391-1397.

35 Mostard RL, Van Kuijk SM, Verschakelen JA, et al. A predictive tool for an effective use of ${ }^{18} \mathrm{~F}$-FDG PET in assessing activity of sarcoidosis. BMC Pulm Med 2012; 12: 57.

36 Keijsers RG, van den Heuvel DA, Grutters JC. Imaging the inflammatory activity of sarcoidosis. Eur Respir J 2013; 41: 743-751.

37 Keijsers RG, Verzijlbergen EJ, van den Bosch JM, et al. ${ }^{18} \mathrm{~F}-\mathrm{FDG}$ PET as a predictor of pulmonary function in sarcoidosis. Sarcoidosis Vasc Diffuse Lung Dis 2011; 28: 123-129.

38 Mostard RL, Verschakelen JA, van Kroonenburgh MJ, et al. Severity of pulmonary involvement and ${ }^{18}$ F-FDG PET activity in sarcoidosis. Respir Med 2013; 107: 439-447.

39 Keijsers RG, Verzijlbergen JF, van Diepen DM, et al. ${ }^{18}$ F-FDG PET in sarcoidosis: an observational study in 12 patients treated with infliximab. Sarcoidosis Vasc Diffuse Lung Dis 2008; 25: 143-149. 